\title{
Effect of apolipoprotein A1 genetic polymorphisms on lipid profiles and the risk of coronary artery disease
}

\author{
BiHong Liao ${ }^{1 \dagger}$, KeQi Cheng ${ }^{1 \dagger}$, ShaoHong Dong ${ }^{1}$, HuaDong Liu ${ }^{1}$ and ZhengLei $\mathrm{Xu}^{2^{*}}$
}

\begin{abstract}
Background: The disorder of lipid metabolism and genetic predisposition are major risk factors for coronary artery disease (CAD). Variants in the apolipoprotein A1 (APOA1) gene play an important role in the regulation of lipids. The objective of the present study was to investigate the effect of two polymorphisms ( $-75 \mathrm{G} / \mathrm{A}$ and $+83 \mathrm{C} / \mathrm{T})$ of $A P O A 1$ on lipid profiles and the risk of CAD.
\end{abstract}

Methods: A total number of 300 subjects with CAD and 300 age and sex matched healthy controls were enrolled for the study. Genotyping of the APOA1 was performed by polymerase chain reaction-restriction fragment length polymorphism (PCR-RFLP) combined with gel electrophoresis, and then confirmed by direct sequencing.

Results: The frequencies of APOA1 -75 AA genotype [odds ratio $(O R)=0.50,95 \%$ confidence interval $(C I)=0.28$, $0.88 ; P=0.02]$ and $A P O A 1-75 \mathrm{~A}$ allele $(\mathrm{OR}=0.76,95 \% \mathrm{Cl}=0.59,0.98 ; P=0.04)$ were significantly lower in $C A D$ than in controls. The APOA1 -75 A allele was significantly associated with increasing serum concentrations of ApoA1 and high-density lipoprotein cholesterol (HDL-C) $(P<0.001)$.

Conclusions: The individuals with the APOA1-75 A allele were likely to have a lower risk of CAD as a result of its effect on higher serum concentrations of ApoA1 and HDL-C.

Keywords: Apolipoprotein A1, Gene polymorphism, Coronary artery disease, Lipid

\section{Background}

Coronary artery disease (CAD) is the leading cause of mortality and morbidity in the world [1]. Although the precise mechanisms responsible for the onset of CAD are still unknown, it is a multifactorial disease, which is influenced by interacting endogenous and exogenous factors $[2,3]$. The major risk factors of CAD are age, stress, hypertension, diabetes mellitus, hyperlipidemia, smoking, high alcohol consumption, family history of CAD and obesity [4-8]. The disorder of lipid metabolism and genetic predisposition are major risk factors for CAD [9-11]. It has been estimated that genetic risk factors explain approximately $20 \%-60 \%$ of CAD cases

\footnotetext{
* Correspondence: zhengleixu@hotmail.com

${ }^{+}$Equal contributors

${ }^{2}$ Department of Internal Medicine, Second Clinical Medical College of Jinan University, Shenzhen People's Hospital, NO. 1017 East Gate Road, Shenzhen 518000, Guangdong Province, China

Full list of author information is available at the end of the article
}

[12]. Some genes have been investigated for their involvement in the development of CAD $[13,14]$.

Apolipoprotein A1 (apoA1) is the major apolipoprotein constituent of the high-density lipoprotein (HDL) and is involved in reverse cholesterol transport [15]. $\mathrm{Up}$ to now, several single-nucleotide polymorphisms (SNPs) have been identified in the APOA1 gene located on the long arm of chromosome 11 [16]. A common G-to-A transition located - 75 base pairs (bp) upstream from the transcription start site of the APOA1 gene has been studied extensively [17]. Another polymorphism site was identified in the first intron of the APOA1 gene that involves transition of $\mathrm{C}$-to- $\mathrm{T}$ at $+83 \mathrm{bp}$ that has also been shown to affect HDL and apoA1 levels $[18,19]$.

Although three case-control studies have investigated the association between $A P O A 1$ polymorphisms (-75 G/A and $+83 \mathrm{C} / \mathrm{T})$ and the risk of $\mathrm{CAD}$, these studies have 
reported conflicting results [20-22]. The objective of the present study was to investigate the effect of two polymorphisms (-75 G/A and $+83 \mathrm{C} / \mathrm{T})$ of $A P O A 1$ on lipid profiles and the risk of $\mathrm{CAD}$ in a Chinese population.

\section{Methods}

Study population

A total number of 300 subjects with CAD and 300 age and sex matched healthy controls were enrolled for the study between July 2011 and June 2014 in the Second Clinical Medical College of Jinan University, China. CAD cases were defined as those having severe angiostenosis $(>50 \%)$ in at least one major coronary artery determined by angiography based on WHO criteria. CAD cases were selected randomly from patients admitted to the hospital and who fulfilled the inclusion criteria. The control group was composed of age and sex matched healthy subjects who had undergone a coronary angiography in the same recruitment period as the CAD patients, with normal ECG, negative stress test, without family history of CAD or other cardiovascular diseases or angiographic evidence of CAD. The study was approved by the Institutional Ethical Committee of the Second Clinical Medical College of Jinan University. A signed informed consent was obtained from all participants in the study. Venous blood was collected in evacuated tubes after an overnight fast of 12 to $14 \mathrm{~h}$.

\section{Biochemical analysis}

Serum total cholesterol (TC), triglycerides (TG), highdensity lipoprotein cholesterol (HDL-C) were measured by the clinical chemistry department using commercial kits following the manufacturer instructions. Serum lowdensity lipoprotein cholesterol (LDL-C) and very-lowdensity lipoprotein cholesterol (VLDL-C) were calculated using the Friedwald's formula. The immunoturbidimetric assay was used to quantify the plasma concentrations of ApoA1 and ApoB.

\section{DNA extraction and genotyping}

Total genomic DNA was isolated from peripheral blood leukocytes by the commercially available Qiagen kit (QIAGEN Inc., Valencia, CA, USA). Polymerase chain reaction restriction fragment length polymorphism (PCR-RFLP) assay was performed to assess the APOA1 gene polymorphisms. Based on the GenBank reference sequence, the PCR primer pair used as follows: forward: $5^{\prime}$-AGG GAC AGA GCT GAT CCT TGA ACT CTT AAG-3', and reverse: 5'-TTA GGG GAC ACC TAG CCC TCA GGA AGA GCA-3'. The amplified PCR products were digested with 10 units of the restriction endonuclease enzyme $M s p \mathrm{I}$ overnight. The digested fragments were resolved on a $3 \%$ agarose gel and stained with ethidium bromide for visualization under UV light. The presence of the $M s p I$ restriction stie at $-75 \mathrm{bp}$ ( $\mathrm{G}$ allele) and at $+83 \mathrm{bp}$ (C allele) in the 433 bp product resulted in four fragments of 45,66 , 113 and $209 \mathrm{bp}$. The absence of the restriction site at $-75 \mathrm{bp}$ (A allele) resulted in three fragments of 45,179 and $209 \mathrm{bp}$. The absence of the restriction site at $+83 \mathrm{bp}$ ( $\mathrm{T}$ allele) created a larger fragment of $254 \mathrm{bp}$ instead of two fragments of 45 and 209 bp. For quality control, we performed double sampling PCR-RFLP in more than $10 \%$ of the samples and found no differences, and then confirmed by direct sequencing.

Table 1 Distribution of the various phenotypic variables in cases and controls

\begin{tabular}{llll}
\hline & CAD $(n=300)$ & Controls $(n=300)$ & $P$ \\
\hline Age (years) & $56.7 \pm 9.9$ & $56.1 \pm 9.7$ & 0.45 \\
Sex (Male/Female) & $238 / 62$ & $231 / 69$ & 0.49 \\
Smoking status (Ever/Never) & $84 / 216$ & $46 / 254$ & $<0.001$ \\
Diabetes (Positive/Negative) & $74 / 226$ & $42 / 258$ & 0.001 \\
Hypertension (Positive/Negative) & $163 / 137$ & $144 / 156$ & 0.12 \\
Obesity (Positive/Negative) & $87 / 213$ & $51 / 249$ & 0.001 \\
Hyperlipidemia (Positive/Negative) & $93 / 207$ & $49 / 251$ & $<0.001$ \\
TG (mg/dL) & $192.1 \pm 86.7$ & $167.5 \pm 77.4$ & $<0.001$ \\
TC (mg/dL) & $198.7 \pm 58.4$ & $185.3 \pm 50.1$ & 0.003 \\
HDL-C (mg/dL) & $33.7 \pm 11.6$ & $38.9 \pm 12.9$ & $<0.001$ \\
LDL-C (mg/dL) & $126.6 \pm 37.4$ & $112.9 \pm 33.8$ & $<0.001$ \\
VLDL-C (mg/dL) & $38.4 \pm 21.5$ & $33.5 \pm 20.3$ & 0.004 \\
ApoA1 (mg/dL) & $123.5 \pm 22.3$ & $131.9 \pm 23.5$ & $<0.001$ \\
ApoB (mg/dL) & $91.4 \pm 27.3$ & $90.6 \pm 26.7$ & 0.72 \\
\hline Abbiar
\end{tabular}

Abbreviations: CAD, coronary artery disease; TG, triglyceride; TC, total cholesterol; HDL-C, high-density lipoprotein cholesterol; LDL-C, low-density lipoprotein cholesterol; VLDL-C, very-low-density lipoprotein cholesterol; Apo, apolipoprotein 
Table 2 Genotype and allele frequencies of APOA1 gene polymorphisms (-75 G/A and $+83 \mathrm{C} / \mathrm{T})$ among CAD cases and healthy controls

\begin{tabular}{|c|c|c|c|c|}
\hline & Cases $(n=300)$ & Controls $(n=300)$ & OR $(95 \% \mathrm{Cl})$ & P \\
\hline \multicolumn{5}{|c|}{ Genotype } \\
\hline GG & 175(58.3) & $161(53.7)$ & 1.00(Reference) & \\
\hline GA & 104(34.7) & $100(33.3)$ & $0.96(0.68,1.36)$ & 0.80 \\
\hline AA & $21(7.0)$ & $39(13.0)$ & $0.50(0.28,0.88)$ & 0.02 \\
\hline CC & $221(73.7)$ & $230(76.7)$ & 1.00(Reference) & \\
\hline$C T$ & $54(18.0)$ & $39(13.0)$ & $1.44(0.92,2.26)$ & 0.11 \\
\hline$\Pi$ & $25(8.3)$ & $31(10.3)$ & $0.84(0.48,1.47)$ & 0.54 \\
\hline \multicolumn{5}{|c|}{ Allele } \\
\hline G & $454(75.7)$ & $422(70.3)$ & 1.00(Reference) & \\
\hline A & $146(24.3)$ & 178(29.7) & $0.76(0.59,0.98)$ & 0.04 \\
\hline C & 496(82.7) & 499(83.2) & 1.00(Reference) & \\
\hline $\mathrm{T}$ & 104(17.3) & 101(16.8) & $1.04(0.77,1.40)$ & 0.82 \\
\hline
\end{tabular}

APOA1, apolipoprotein $A 1 ; C A D$, coronary artery disease; $O R$, odds ratio; $\mathrm{Cl}$, confidence interval

\section{Statistical analysis}

Statistical analyses were performed by SPSS software for Windows (SPSS 11.0 SPSS Inc., Chicago, IL). Allele frequencies were calculated by the gene counting method. Differences between continuous variables were assessed by Student's $t$ test, while those between categorical variables were evaluated using $x^{2}$ test. The existence of differences in genotypic frequencies between groups was assessed by means of $x^{2}$ test. The odds ratio (OR) and $95 \%$ confidence intervals (CI) were also calculated. $P<$ 0.05 was required for statistical significance.

\section{Results}

\section{Characteristics of participants}

Distribution of the various phenotypic variables in cases and controls were shown in Table 1. No significant differences were found between the CAD cases and controls in age, sex, hypertension and ApoB (Table 1). HDL-
$C$ and ApoA1 were significantly decreased $(P<0.001)$, but TG $(P<0.001)$, TC $(P=0.003)$, LDL-C $(P<0.001)$ and VLDL-C $(P=0.004)$ levels were significantly increased in patients as compared to controls. Multiple logistic regression analysis of known predictors of CAD confirmed the independent role of smoking status $(P<0.001)$, diabetes $(P=0.001)$, obesity $(P=0.001)$, hyperlipidemia $(P<0.001)$ and ApoA1 $(P<0.001)$ as risk factors of CAD (Table 1$)$.

\section{APOA1 -75 G/A polymorphisms, lipids and CAD}

The frequencies of $A P O A 1-75$ AA genotype $(\mathrm{OR}=0.50$, $95 \% \mathrm{CI}=0.28,0.88 ; P=0.02)$ and $A P O A 1-75$ A allele $(\mathrm{OR}=0.76,95 \% \mathrm{CI}=0.59,0.98 ; P=0.04)$ were significantly lower in CAD than in controls (Table 2). The APOA1 -75 A allele was significantly associated with increasing serum concentrations of ApoA1 and high-density lipoprotein cholesterol (HDL-C) $(P<0.001)$ (Table 3$)$.

\section{APOA $1+83 \mathrm{C} / \mathrm{T}$ polymorphisms, lipids and CAD}

No association was found between $A P O A 1+83 \mathrm{C} / \mathrm{T}$ polymorphisms and risk of CAD (Table 2).

\section{Discussion}

Many studies have been conducted to test the association of SNPs and CAD. A meta-analysis of thirteen casecontrol studies suggested that thrombomodulin -33G/A and Ala455Val polymorphisms were risk factors for CAD [23, 24]. A meta-analysis of 72 studies including 23,557 cases and 21,526 controls suggested that plasminogen activator inhibitor-1 4G/5G polymorphism was a risk factor for CAD [25]. A meta-analysis of 10,617 cases and 8,302 controls from 37 studies revealed that endothelial nitric oxide synthase $4 \mathrm{~b} / \mathrm{a}$ polymorphisms could be a risk factor for developing CAD, particularly in African populations and population-based subgroups [26]. A meta-analysis of 21 eligible literatures confirmed a protective effect of C242T polymorphism of CYBA gene on CAD in Asian population and indicated that A640G polymorphism of CYBA gene was significantly associated with decreased

Table 3 Lipid profiles of CAD cases and controls according to APOA1 -75 G/A polymorphisms

\begin{tabular}{|c|c|c|c|c|c|c|c|c|}
\hline & \multicolumn{3}{|l|}{ CAD } & \multirow[t]{2}{*}{$P$ value } & \multicolumn{3}{|l|}{ Controls } & \multirow[t]{2}{*}{$P$ value } \\
\hline & GG & GA & $\mathrm{AA}$ & & $\mathrm{GG}$ & $\mathrm{GA}$ & $\mathrm{AA}$ & \\
\hline TG $(m g / d L)$ & $187.1 \pm 79.3$ & $198.9 \pm 92.5$ & $175.5 \pm 86.2$ & 0.72 & $160.5 \pm 57.3$ & $176.1 \pm 62.4$ & $156.9 \pm 59.8$ & 0.68 \\
\hline $\mathrm{TC}(\mathrm{mg} / \mathrm{dL})$ & $192.4 \pm 55.7$ & $206.4 \pm 59.4$ & $203.3 \pm 56.8$ & 0.44 & $178.9 \pm 48.7$ & $194.8 \pm 53.6$ & $191.4 \pm 50.2$ & 0.39 \\
\hline $\mathrm{HDL}-\mathrm{C}(\mathrm{mg} / \mathrm{dL})$ & $30.4 \pm 10.6$ & $36.8 \pm 11.9$ & $41.5 \pm 12.7$ & $<0.001$ & $37.1 \pm 12.0$ & $41.2 \pm 13.6$ & $46.8 \pm 14.5$ & $<0.001$ \\
\hline LDL-C (mg/dL) & $124.6 \pm 36.9$ & $129.8 \pm 40.1$ & $126.7 \pm 38.2$ & 0.87 & $109.7 \pm 30.5$ & $118.4 \pm 36.5$ & $113.2 \pm 33.7$ & 0.69 \\
\hline VLDL-C (mg/dL) & $37.4 \pm 12.4$ & $39.8 \pm 19.7$ & $35.1 \pm 10.6$ & 0.31 & $32.1 \pm 17.6$ & $35.2 \pm 18.4$ & $31.4 \pm 16.2$ & 0.42 \\
\hline ApoA1 (mg/dL) & $114.5 \pm 20.7$ & $127.6 \pm 22.5$ & $138.9 \pm 24.1$ & $<0.001$ & $124.4 \pm 23.5$ & $135.7 \pm 24.3$ & $144.7 \pm 25.8$ & $<0.001$ \\
\hline ApoB (mg/dL) & $86.7 \pm 25.4$ & $97.6 \pm 29.5$ & $90.7 \pm 26.9$ & 0.63 & $88.1 \pm 25.8$ & $93.6 \pm 27.5$ & $89.5 \pm 26.7$ & 0.74 \\
\hline
\end{tabular}

$\mathrm{CAD}$, coronary artery disease; $\mathrm{APOA}$, apolipoprotein $\mathrm{A} 1$; OR, odds ratio; $\mathrm{Cl}$, confidence interval; $\mathrm{TG}$, triglyceride; $\mathrm{TC}$, total cholesterol; $\mathrm{HDL}-\mathrm{C}$, high-density lipoprotein cholesterol; LDL-C, low-density lipoprotein cholesterol; VLDL-C, very-low-density lipoprotein cholesterol; Apo, apolipoprotein 
risk of CAD [27]. A meta-analysis of ten studies suggested there was an increase in the risk of CAD conferred by the E-selectin Ser128Arg polymorphism and the P-selectin thr715Pro polymorphism may be a protective factor of myocardial infarction [28]. A meta-analysis of eighteen studies with 3,546 cases and 3,852 controls suggested that the intercellular adhesion molecule-1 K469E polymorphism was a risk factor for CAD [29]. A meta-analysis of thirty case-control studies suggested that EcoRI and SpIns/Del polymorphisms of the APO B gene significantly increased the risk of CAD [30].

The APOA1 gene polymorphisms were also extensively studied and reported to be associated with other diseases. A hospital-based case-control study found that APOA1 -75 AA genotype was associated with a higher acute lung injury (ALI) risk after cardiopulmonary bypass (CPB) surgery. Those patients with the APOA1 -75 AA genotype and A allele had higher 30-day mortality of ALI after CPB surgery [31]. A case-control study found an association of the APOA1 -75G/A promoter polymorphism with cognitive performance in multiple sclerosis [32]. A prospective case-control study found a positive association between APOA1 -75 A allele carriers and breast cancer risk [33]. A pilot study in a north Indian population suggested that $A P O A 1$ polymorphisms (-75 G/A and $+83 \mathrm{C} / \mathrm{T})$ might be susceptibility to myocardial infarction [19]. A case-control study found the APOA1 -75 A allele was associated with an increased risk for Alzheimer's disease [34]. A Brazilian elderly cohort showed that APOA1 polymorphisms (-75 G/A and $+83 \mathrm{C} / \mathrm{T}$ ) could be as risk factors for hypertension and obesity [35]. A case-control study suggested that the APOA1 -75 G/A polymorphism was associated with gallstone disease and shows sex-specific differences [36].

Although our results revealed that the individuals with the APOA1 -75 A allele were likely to have a lower risk of CAD as a result of its effect on higher serum concentrations of ApoA1 and HDL-C, the exact mechanism is still unclear. However, the results have been inconsistent and inconclusive, with few studies reporting either no association or negative association between APOA1 -75 A allele and plasma lipids [37-39]. Our study was consistent with some other studies [17, 40-44].

Several shortcomings of the present study should be discussed. Firstly, CAD, a multifactorial disease, is influenced by interacting endogenous and exogenous factors, which were not explored in the present study. Secondly, the subjects in this research are only from Han Chinese ethnic group. It would be interesting to conduct similar studies in different populations for comparison. Thirdly, about $50 \%$ cases took statins by which lipid levels are affected. We have adjusted for medicine use in this analysis, but no information could be received on the baseline lipid levels of these cases. Finally, the potential selection bias cannot be avoidable, because this is a hospital based case control study and the subjects may not be representative of the general population.

\section{Conclusions}

In conclusion, our results indicated that the individuals with the APOA1 -75 A allele were likely to have a lower risk of CAD as a result of its effect on higher serum concentrations of ApoA1 and HDL-C. Additional studies are needed to confirm this finding.

\section{Competing interests}

The authors declare that they have no competing interests.

\section{Authors' contributions}

$\mathrm{BHL}, \mathrm{KQC}$ and $\mathrm{ZLX}$ carried out the molecular genetic studies and drafted the manuscript. SHD carried out the genotyping. HDL participated in the design of the study and performed the statistical analysis. BHL, KQC, SHD, HDL and ZLX conceived of the study, and participated in its design and coordination and helped to draft the manuscript. All authors read and approved the final manuscript.

\section{Acknowledgements}

We thank all the participants and the clinicians for their valuable contributions. We also thank all local project coordinators, research assistants, laboratory technicians, and secretaries/administrative assistants.

\section{Author details}

'Department of Cardiology, Second Clinical Medical College of Jinan University, Shenzhen People's Hospital, Shenzhen 518000, Guangdong Province, China. ${ }^{2}$ Department of Internal Medicine, Second Clinical Medical College of Jinan University, Shenzhen People's Hospital, NO. 1017 East Gate Road, Shenzhen 518000, Guangdong Province, China.

Received: 12 March 2015 Accepted: 12 June 2015

Published online: 16 July 2015

\section{References}

1. Ordovas JM, Schaefer EJ. Coronary artery disease, lipid disorders and genetic polymorphisms. Ann Biol Clin (Paris). 1988;46:24-9.

2. Zou JG, Ma YT, Xie X, Yang YN, Pan S, Adi D, Liu F, Chen BD. The association between CYP1A1 genetic polymorphisms and coronary artery disease in the Uygur and Han of China. Lipids Health Dis. 2014;13:145.

3. Schaefer LE, Nechemias C. Endogenous Hormones, Lipid Metabolism, and Coronary Artery Disease. Prog Cardiovasc Dis. 1965;7:449-64.

4. van Hateren KJ, Bilo HJ. Hypertension control and cardiovascular outcomes among patients with diabetes and coronary artery disease. JAMA. 2010;304:1672. author reply 1672-1673.

5. Dunn JP, Ipsen J, Elsom KO, Ohtani M. Risk factors in coronary artery disease, hypertension and diabetes. Am J Med Sci. 1970;259:309-22.

6. Turner RC, Millns H, Neil HA, Stratton IM, Manley SE, Matthews DR, Holman RR. Risk factors for coronary artery disease in non-insulin dependent diabetes mellitus: United Kingdom Prospective Diabetes Study (UKPDS: 23). BMJ. 1998;316:823-8.

7. Connelly PW, Stachenko S, MacLean DR, Petrasovits A, Little JA. The prevalence of hyperlipidemia in women and its association with use of oral contraceptives, sex hormone replacement therapy and nonlipid coronary artery disease risk factors. Canadian Heart Health Surveys Research Group. Can J Cardiol. 1999;15:419-27.

8. Li XL, Hong LF, Luo SH, Guo YL, Zhu CG, Sun J, Dong Q, Qing P, Xu RX, Liu J, et al. Impact of admission triglyceride for early outcome in diabetic patients with stable coronary artery disease. Lipids Health Dis. 2014;13:73.

9. Morita H, Taguchi J, Kurihara H, Kitaoka M, Kaneda H, Kurihara Y, Maemura K, Shindo T, Minamino T, Ohno M, et al. Genetic polymorphism of 5, 10-methylenetetrahydrofolate reductase (MTHFR) as a risk factor for coronary artery disease. Circulation. 1997;95:2032-6. 
10. Neutze J, Cormack B, Kerr B, Pepper L, Ramage C. Contribution of a risk factor clinic to lipid management in patients with coronary artery disease. N Z Med J. 1992;105:97-9.

11. Gruzdeva O, Uchasova E, Dyleva Y, Belik E, Karetnikova V, Shilov A, Barbarash O. Multivessel coronary artery disease, free fatty acids, oxidized LDL and its antibody in myocardial infarction. Lipids Health Dis. 2014;13:111.

12. Kraus WE. Genetic approaches for the investigation of genes associated with coronary heart disease. Am Heart J. 2000;140:S27-35.

13. Verdoia M, Cassetti E, Schaffer A, Di Giovine G, De Luca G: Platelet glycoprotein Illa Leu33Pro gene polymorphism and coronary artery disease: A meta-analysis of cohort studies. Platelets 2014:1-6. doi: 10.3109/ 09537104.2014 .948839$.

14. Zhang Z, Chu G, Yin RX. Apolipoprotein M T-778C polymorphism is associated with serum lipid levels and the risk of coronary artery disease in the Chinese population: a meta-analysis. Lipids Health Dis. 2013;12:135.

15. Segrest JP, Li L, Anantharamaiah GM, Harvey SC, Liadaki KN, Zannis V. Structure and function of apolipoprotein A-I and high-density lipoprotein. Curr Opin Lipidol. 2000;11:105-15.

16. Karathanasis SK. Apolipoprotein multigene family: tandem organization of human apolipoprotein Al, CIII, and AIV genes. Proc Natl Acad Sci U S A. 1985;82:6374-8.

17. Saha N, Tay JS, Low PS, Humphries SE. Guanidine to adenine (G/A) substitution in the promoter region of the apolipoprotein $\mathrm{Al}$ gene is associated with elevated serum apolipoprotein Al levels in Chinese non-smokers. Genet Epidemiol. 1994;11:255-64.

18. Wang XL, Badenhop R, Humphrey KE, Wilcken DE. New Mspl polymorphism at +83 bp of the human apolipoprotein Al gene: association with increased circulating high density lipoprotein cholesterol levels. Genet Epidemiol. 1996;13:1-10.

19. Dawar R, Gurtoo A, Singh R. Apolipoprotein A1 gene polymorphism (G-75A and $(+83 T$ ) in patients with myocardial infarction: a pilot study in a north Indian population. Am J Clin Pathol. 2010;134:249-55.

20. Rai TS, Khullar M, Sehrawat BS, Ahuja M, Sharma PK, Vijayvergiya R, Grover A. Synergistic effect between apolipoprotein $\mathrm{E}$ and apolipoprotein $\mathrm{A} 1$ gene polymorphisms in the risk for coronary artery disease. Mol Cell Biochem. 2008:313:139-46.

21. Shanker J, Perumal G, Rao VS, Khadrinarasimhiah NB, John S, Hebbagodi S, Mukherjee M, Kakkar W. Genetic studies on the APOA1-C3-A5 gene cluster in Asian Indians with premature coronary artery disease. Lipids Health Dis. 2008:7:33.

22. Zou Y, Hu D, Yang X, Jia X, Wang L, Cui L, Liu X, Gao M, Wei Y, Xu Z. Relationships among apolipoprotein A1 gene polymorphisms, lipid levels and coronary atherosclerosis disease. Chin Med J (Engl). 2003;116:665-8.

23. Wang H, Dong P. Thrombomodulin -33G/A and Ala455Val polymorphisms are associated with the risk of coronary artery disease: a meta-analysis including 12584 patients. Coron Artery Dis. 2015;26:72-7.

24. Zhang S, Zhang Z, Zhang F, Wei C, Bu Y, Zheng S, Su D. Association between thrombomodulin polymorphisms and coronary artery disease risk: a meta-analysis. Med Sci Monit. 2014:20:1407-12.

25. Zhang $H$, Dong $P$, Yang $X$, Liu Z. Plasminogen activator inhibitor-1 4G/5G polymorphism is associated with coronary artery disease risk: a meta-analysis. Int J Clin Exp Med. 2014;7:3777-88.

26. Yang Y, Du K, Liu Z, Lu X. Endothelial nitric oxide synthase (eNOS) 4b/a gene polymorphisms and coronary artery disease: evidence from a meta-analysis. Int J Mol Sci. 2014;15:7987-8003.

27. Xu Q, Yuan F, Shen X, Wen H, Li W, Cheng B, Wu J. Polymorphisms of C242T and A640G in CYBA gene and the risk of coronary artery disease: a meta-analysis. PLoS One. 2014;9:e84251.

28. Wu Z, Lou Y, Lu L, Liu Y, Chen Q, Chen X, Jin W. Heterogeneous effect of two selectin gene polymorphisms on coronary artery disease risk: a meta-analysis. PLoS One. 2014;9:e88152.

29. Li D, Qu C, Dong P. The ICAM-1 K469E polymorphism is associated with the risk of coronary artery disease: a meta-analysis. Coron Artery Dis. 2014:25:665-70

30. Chiodini BD, Barlera S, Franzosi MG, Beceiro VL, Introna M, Tognoni G. APO B gene polymorphisms and coronary artery disease: a meta-analysis. Atherosclerosis. 2003;167:355-66.

31. Tu J, Zhang B, Chen Y, Liang B, Liang D, Liu G, He F. Association of apolipoprotein A1-75 G/A polymorphism with susceptibility to the development of acute lung injury after cardiopulmonary bypass surgery. Lipids Health Dis. 2013;12:172.
32. Koutsis G, Panas M, Giogkaraki E, Karadima G, Sfagos C, Vassilopoulos D. An APOA1 promoter polymorphism is associated with cognitive performance in patients with multiple sclerosis. Mult Scler. 2009;15:174-9.

33. Hamrita B, Ben Nasr H, Gabbouj S, Bouaouina N, Chouchane L, Chahed K. Apolipoprotein A1-75 G/A and $+83 \mathrm{C} / \mathrm{T}$ polymorphisms: susceptibility and prognostic implications in breast cancer. Mol Biol Rep. 2011;38:1637-43.

34. Vollbach H, Heun R, Morris CM, Edwardson JA, McKeith IG, Jessen F, Schulz A, Maier W, Kolsch H. APOA1 polymorphism influences risk for early-onset nonfamiliar AD. Ann Neurol. 2005;58:436-41.

35. Chen ES, Mazzotti DR, Furuya TK, Cendoroglo MS, Ramos LR, Araujo LQ, Burbano RR, de Arruda Cardoso Smith M. Apolipoprotein A1 gene polymorphisms as risk factors for hypertension and obesity. Clin Exp Med. 2009:9:319-25

36. Dixit M, Choudhuri G, Saxena R, Mittal B. Association of apolipoprotein A1-C3 gene cluster polymorphisms with gallstone disease. Can J Gastroenterol. 2007;21:569-75.

37. Barre DE, Guerra R, Verstraete R, Wang Z, Grundy SM, Cohen JC. Genetic analysis of a polymorphism in the human apolipoprotein A-I gene promoter: effect on plasma HDL-cholesterol levels. J Lipid Res. 1994;35:1292-6.

38. Civeira F, Pocovi M, Cenarro A, Garces C, Ordovas JM. Adenine for guanine substitution -78 base pairs 5 ' to the apolipoprotein (APO) A-I gene: relation with high density lipoprotein cholesterol and APO A-I concentrations. Clin Genet. 1993;44:307-12

39. Wang XL, Liu SX, McCredie RM, Wilcken DE. Polymorphisms at the 5'-end of the apolipoprotein Al gene and severity of coronary artery disease. J Clin Invest. 1996;98:372-7.

40. Jeenah M, Kessling A, Miller N, Humphries S. G to A substitution in the promoter region of the apolipoprotein $\mathrm{Al}$ gene is associated with elevated serum apolipoprotein Al and high density lipoprotein cholesterol concentrations. Mol Biol Med. 1990;7:233-41.

41. Meng QH, Pajukanta P, Valsta L, Aro A, Pietinen P, Tikkanen MJ. Influence of apolipoprotein A-1 promoter polymorphism on lipid levels and responses to dietary change in Finnish adults. J Intern Med. 1997;241:373-8.

42. Pagani F, Sidoli A, Giudici GA, Barenghi L, Vergani C, Baralle FE. Human apolipoprotein $\mathrm{A}-\mathrm{I}$ gene promoter polymorphism: association with hyperalphalipoproteinemia. J Lipid Res. 1990;31:1371-7.

43. Paul-Hayase H, Rosseneu M, Robinson D, Van Bervliet JP, Deslypere JP, Humphries SE. Polymorphisms in the apolipoprotein (apo) Al-CIII-AIV gene cluster: detection of genetic variation determining plasma apo Al, apo CIII and apo AIV concentrations. Hum Genet. 1992;88:439-46.

44. Xu CF, Angelico F, Del Ben M, Humphries S. Role of genetic variation at the apo Al-CIII-AIV gene cluster in determining plasma apo Al levels in boys and girls. Genet Epidemiol. 1993;10:113-22.

\section{Submit your next manuscript to BioMed Central and take full advantage of:}

- Convenient online submission

- Thorough peer review

- No space constraints or color figure charges

- Immediate publication on acceptance

- Inclusion in PubMed, CAS, Scopus and Google Scholar

- Research which is freely available for redistribution 